\title{
BMJ Open Prevalence of HIV at the Kokoyo informal gold mining site: what lies behind the glitter of gold with regard to HIV epidemics in Mali? A community- based approach (the ANRS-12339 Sanu Gundo cross-sectional survey)
}

\author{
Luis Sagaon-Teyssier, ${ }^{1,2}$ Hubert Balique, ${ }^{2}$ Fodié Diallo, ${ }^{3}$ Nikos Kalampalikis, ${ }^{4}$ \\ Marion Mora, ${ }^{1,2}$ Michel Bourrelly, ${ }^{1,2}$ Marie Suzan-Monti, ${ }^{1,2}$ Bruno Spire, ${ }^{1,2}$ \\ Bintou Dembélé Keita ${ }^{3}$
}

To cite: Sagaon-Teyssier L, Balique $\mathrm{H}$, Diallo $\mathrm{F}$, et al. Prevalence of HIV at the Kokoyo informal gold mining site: what lies behind the glitter of gold with regard to HIV epidemics in Mali? A community-based approach (the ANRS-12339 Sanu Gundo cross-sectional survey). BMJ Open

2017;7:e016558. doi:10.1136/ bmjopen-2017-016558

- Prepublication history for this paper is available online. To view these files please visit the journal online (http://dx.doi. org/10.1136/bmjopen-2017016558).

Received 23 February 2017

Revised 15 June 2017

Accepted 21 June 2017

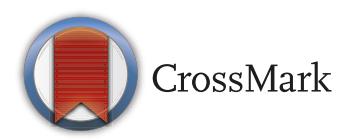

For numbered affiliations see end of article.

Correspondence to

Dr. Luis Sagaon-Teyssier;

luis.sagaon-teyssier@inserm.fr

\section{ABSTRACT}

Objectives The aim of this article was to estimate HIV prevalence and the factors associated with HIV seropositivity in the population living and working at the informal artisanal small-scale gold mining (IASGM) site of Kokoyo in Mali, using data from the Sanu Gundo survey. Our main hypothesis was that HIV prevalence is higher in the context of IASGM than in the country as a whole.

Design The ANRS-12339 Sanu Gundo was a crosssectional survey conducted in December 2015.

The quantitative survey consisted of face-to-face administration of questionnaires. Five focus groups were conducted for the qualitative survey. HIV prevalence was calculated for the sample, and according to the type of activity performed in IASGM.

Settings The IASGM site of Kokoyo, one of the largest sites in Mali (between 6000 and 1000 people).

Participants 224 respondents: $37.5 \%$ were gold-diggers, $33 \%$ retail traders, $6.7 \%$ tombolomas (ie, traditional guards) and $9 \%$ female sex workers. The remaining $13.8 \%$ reported another activity (mainly street vending).

Primary and secondary outcome measures HIV prevalence and HIV prevalence according to subgroup, as defined by their activity at the Kokoyo IASGM. A probit logistic regression was implemented to estimate the characteristics associated with HIV seropositivity. Results HIV prevalence for the total sample was $8 \%$ $(95 \% \mathrm{Cl} 7.7 \%$ to $8.3 \%)$, which is much higher than the 2015 national prevalence of 1.3\%Joint United Nations Programme on HIV/AIDS (UNAIDS). The probability of HIV seropositivity was $7.8 \%(p=0.037)$ higher for female non-sex workers than for any other category, and this probability increased significantly with age. Qualitative data revealed the non-systematic use of condoms with sex workers; and long distance from health services was the main barrier to accessing care.

Conclusions Integrated policymaking should pay special attention to infectious diseases among populations in IASGM zones. Bringing information/prevention activities
Strengths and limitations of this study

- This is the first study conducted in an informal and artisanal small-scale gold mining site in Mali including all of the people directly or indirectly involved in the site's activities.

- This study was implemented using a communitybased research approach, the survey design and research questions being developed in collaboration with representatives of the mine of Kokoyo.

- The highest HIV prevalence was found among female non-sex workers (13\%), which highlights the importance of focusing on high-risk less studied populations.

- A large proportion of participants in the survey had never had an HIV test, which highlights the importance of 'close proximity health services.'

- The cross-sectional design of the Sanu Gundo survey did not enable us to analyse changes over time concerning several socioeconomic and behavioural aspects, such as living and working conditions, seasonal mobility or sexual behaviour.

closer to people working in gold mining zones is an urgent public health action.

\section{INTRODUCTION}

The poverty-driven activities and demographic conditions in the world's informal artisanal small-scale gold mining (IASGM) sector contribute to its vulnerability to infectious diseases including HIV. This disease is recognised as one of the main public health issues in this sector, and potentially concerns almost 15 million people involved in IASGM activities across 70 countries. ${ }^{1}$ Despite the high risk of transmission, ${ }^{23}$ and sustained 
spread of the disease, ${ }^{45}$ very little is known about HIV epidemics in IASGM sites. Existing HIV literature on people working and living in gold mining sites mainly focuses on behavioural aspects, such as prevention, ${ }^{6}$ attitudes towards voluntary counselling and testing, ${ }^{78}$ the link between alcohol consumption and HIV, ${ }^{9}$ and the role of gender in the fight against HIV. ${ }^{310} 11$ Furthermore, most studies have either been conducted among workers in industrial gold mines or in mining communities near gold-bearing zones which are not exclusively related to the IASGM sector. This is also the case of the few studies examining HIV prevalence, which in South Africa in the last decade was measured at approximately $25 \%,{ }^{3} 1213$ at 22.3\% for a group of Mozambican gold miners in 2012, and at $4.5 \%$ and $6.4 \%$ for Guinea in 2001 and 2007, respectively. ${ }^{14}$ We found only one study concerning an IASGM site, specifically in the Amazon region of Guyana. HIV prevalence there was $6.5 \%{ }^{15}$ In addition, these studies principally focus on gold miners themselves and/ or other presupposed most-at-risk groups (eg, female sex workers), with little attention given to other categories of potentially high-risk people such as gold-diggers (ie, miners working in the informal sector), women who are not sex workers and street vendors, all of whom play an important role in the transmission and/or mobility of HIV. Indeed, focusing only on gold miners and not including these other high-risk groups may be detrimental to the fight against HIV, ${ }^{2}$ as demonstrated by Clift $e t \mathrm{ll}^{16}$ in a community near two industrial gold mines in Tanzania, where HIV prevalence was lower in mine workers $(6 \%)$ than in men and women living at the mines but not directly involved in mining ( $16 \%$ and $18 \%$, respectively).

Gold mining is one of the cornerstones of the Malian economy, representing almost $70 \%$ of the country's total exports and $8 \%$ of the gross domestic product in 2013. ${ }^{17-19}$ Between 200000 and 400000 persons are estimated to be directly concerned by IASGM activities. ${ }^{20}{ }^{21}$ Despite the economic importance of the sector, little attention has been paid to health, as demonstrated by both the poor medical services provided in these sites ${ }^{22} 23$ and the increasing demand for health, especially concerning HIV. The high prevalence observed in some key populations provides a picture of the situation people may face in these sites. A demographic and health survey (Enquête Démographique et de Santé, (EDSMV)) conducted in Mali in 2012 showed that HIV prevalence among female sex workers $(24.2 \%)$, female street vendors $(3.7 \%)$ and truckers $(2.7 \%)$ was much higher than the national prevalence of approximately $1.2 \%$ in the same year. Different reports on IASGM in Mali have highlighted the urgent need to include the health dimension in economic-based research programmes, especially concerning HIV. Community-based activities (eg, prevention, screening, counselling, and so on) could help do this as they could help provide a greater understanding of the heterogeneity of IASGM, the functioning of this informal labour market ${ }^{24}$ and the impact of IASGM sector on the transmission and spread of infectious diseases.
We conducted the ANRS-12339 Sanu Gundo survey of the IASGM site at Kokoyo in Mali's Koulikoro region in December 2015 using a community-based research approach. The objective of this article was to estimate HIV prevalence-using the Sanu Gundo survey-in different groups present at Kokoyo, and the factors associated with HIV seropositivity.

\section{METHODS}

\section{Design and settings}

The ANRS-12339 Sanu Gundo cross-sectional survey was conducted in December 2015 at Kokoyo (for 2 weeks), one of the largest IASGM sites in Mali with a population oscillating between 6000 and 10000 people, depending on the season (rainy/dry). In collaboration with the Chamber of Mines and the Mines Ministry, this site was chosen for its geographical location because of the great deal of cultural heterogeneity there. People come from other Malian regions and from neighbouring countries (Burkina Faso, Guinea, Nigeria and Niger). All procedures and documents used were validated by both French (CCTIRS No. 15.917) and Malian (No. 2015/65/CE/ FMPOS) ethics committees.

The study started with conversations about global health topics with a focus on HIV/STI (sexually transmitted infection) prevention which were facilitated by ARCAD-SIDA members. Participants in the conversations were informed about the community-based services provided by the mobile ARCAD-SIDA unit, including the provision of a medical check-up and essential medicines including those for treating STI. Furthermore, ARCADSIDA proposed rapid tests for HIV and invited people to take part in the survey. For HIV screening, ARCAD-SIDA follows the Malian Ministry of Health recommendations using Determine Rapid Tests, and ImmunoComb II for confirmation. ARCAD-SIDA provided counselling about the importance of being treated to participants testing HIV positive, and referred them to regional healthcare centres (Centre de Santé de Référence, CSREF) for blood assessment and inclusion in treatment and follow-up programmes.

Participants in the conversations were then invited to participate in the qualitative and quantitative surveys (they could choose either or both) which formed the basis for the ANRS-12339 Sanu Gundo survey. Community-based agents sent those interested to the Malian team of researchers, who in turn provided detailed information about the content of the survey, its main objectives and the advantages/risks of participating in this kind of survey. Survey participants provided written formal consent to participate in the survey(s) by signing a letter of consent.

\section{Participants}

Eligibility criteria included: (1) aged 18 years or older; (2) able to speak French, Bambara or English; (3) able to provide written consent to participate. Persons under 
the effects of alcohol and/or drugs were excluded. For the quantitative survey, 224 participants constituted the convenience sample. In order to reduce any potential over-representation and under-representation sampling bias, ARCAD-SIDA activities were conducted every day at different time slots and locations at the site in order to adapt participant recruitment to the work schedule of the different categories of people living there. To those who agreed to participate in the survey(s), a brief face-to-face questionnaire was administered by trained investigators who collected information about the following: (1) sociodemographic and socioeconomic characteristics: age (continuous variable), gender, marital status, country of residence, educational level and weekly earnings (dichotomised at the median of 14500 Francs de la Communauté Financière en Afrique (FCFA), approximately US\$24.26); (2) type of activity and mobility between sites; (3) HIV awareness, assessed with the following questions: 'Have you heard about HIV?', 'Have you ever been tested for HIV before today?', 'Do you know your HIV status?'; (4) risky behaviours: alcohol and drugs consumption, sexual self-definition, type(s) and frequency of intercourse; (5) perceived health status, assessed with the following question: 'How do you consider your state of health today?', with possible answers including 'very poor', 'poor', 'moderate', 'good' and 'very good'. This variable was equal to 1 for those perceiving their health was good or very good, and 0 for those perceiving they had poor or very poor health. For the qualitative survey, purposive sampling was implemented. This seemed to be the most suitable sampling method as the main objective of the qualitative survey was to collect information about prevention and access to care for HIV/STI among specific groups. The sample size for each group was fixed between five and eight survey participants in order to ensure diversity among them. Five activity-specific focus groups were organised: Malian gold-diggers, non-Malian gold-diggers, female sex workers, female non-sex workers and people guaranteeing the organisational functioning at the gold mine site (damantiguis and tombolomas).

\section{Statistical analyses}

The sample was described and HIV prevalence calculated both for the overall sample, and for the different subgroups listed above (ie, according to the type of activity in the gold mining site). A probit logistic regression was implemented to estimate the characteristics associated with the probability of HIV seropositivity. Given the nature of the normal distribution assumption of the error term in the probit estimation, coefficients are not affected by the presence of extreme values in independent variables. Furthermore, probit regression allows the computation of marginal effects that are more flexible and more informative than $\mathrm{ORs}^{25}{ }^{26}$ which tend to be larger in the presence of rare events and are in any case preferred for small samples. ${ }^{27}$ Marginal effects, $\mathrm{dF}$ / $\mathrm{dX}$, are interpreted as instantaneous rates of change: for a dichotomous explanatory variable, a marginal effect shows how predicted probabilities change when the variable changes from 0 to 1 . All statistical analyses were performed using R software. ${ }^{28}$

\section{Qualitative data analysis}

Focus groups were audio-recorded and transcribed. The principle of thematic encoding developed by Flick ${ }^{29}$ for the analysis of interviews was applied as for other studies with focus groups. ${ }^{30}$ Therefore, thematic and pragmatic dimensions were combined into a dialogical unit to highlight patterns specific to the different groups. Lexical analysis was carried out using both Alceste and MAXQDA software. The different dimensions were cross-classified to generate new insights about the organisation of the data (ie, how common themes are linked together, specific interactions intra and intergroups, and so on).

\section{RESULTS}

\section{Sample characteristics}

The quantitative survey was conducted on a convenience sample of 224 participants interested in prevention and medical activities provided by ARCAD-SIDA (table 1): 101 women $(45.1 \%)$ and 123 men $(54.9 \%)$. There was a significant difference in average age between both genders: 25 and 29 years old, respectively. With respect to participants' main residence, 133 (59.4\%) declared they lived in Mali: $28.5 \%$ in Kokoyo (ie, autochthonous) and $71.5 \%$ from different cities (ie, non-autochthonous) including Danga (the nearest) and Timbuktu (the farthest). The remaining 91 participants $(40.6 \%)$ declared another country as their principal place of residence. With respect to marital status, 158 participants $(70.5 \%$ of the whole sample) declared they were married or lived in a couple. Among them, 50.6\% lived with their spouse in Kokoyo and the remaining $49.4 \%$ were geographically single. Of the 86 married/in-a-couple men who did not live with their spouse in Kokoyo, $72.1 \%$ declared living with another partner at the site. Conversely, the proportion of geographically single women was only $22.2 \%$ among the sample's 72 married/in-a-couple women, and none declared having another partner at the site. Socioeconomic difficulties were observed in terms of educational level, with $49.1 \%$ of the 224 participants reporting they had never been to school. Among the others, $27.7 \%$ and $9.8 \%$ had, respectively, a primary and secondary school educational level, $12.1 \%$ had a Koranic educational background and $1.3 \%$ declared having postsecondary school education. With respect to their activity in Kokoyo, among the 224 respondents $37.5 \%$ were gold-diggers, $33 \%$ retail traders, $6.7 \%$ tombolomas, $9 \%$ female sex workers, while $14 \%$ reported another activity (mainly street vending). Approximately half of the sample comprised people living under the poverty threshold of US $\$ 1.9$ per day: $49.3 \%$ compared with $49.1 \%$ in the general Malian population (2009). ${ }^{31}$ Finally, $11.6 \%$ reported mobility between IASGM sites, and declared that Kokoyo was not the first IASGM site where they had worked. 
Table 1 Sample characteristics of participants living in the IASGM site of Kokoyo in Mali $(n=224)$

\begin{tabular}{|c|c|}
\hline Variables & n (\%) \\
\hline \multicolumn{2}{|l|}{ Gender } \\
\hline Male & $123(54.9)$ \\
\hline Female & $101(45.1)$ \\
\hline \multicolumn{2}{|l|}{ Age \pm (years) } \\
\hline Ref: 18-21 & $57(25.4)$ \\
\hline $22-26$ & $60(26.8)$ \\
\hline $27-30$ & $53(23.7)$ \\
\hline $30+$ & $54(24.1)$ \\
\hline \multicolumn{2}{|l|}{ Main residence country } \\
\hline Mali & $133(59.4)$ \\
\hline Other countries & $91(40.6)$ \\
\hline \multicolumn{2}{|l|}{ Marital status } \\
\hline Married or living in a couple & $158(70.5)$ \\
\hline Single, divorced, widowed & $66(29.5)$ \\
\hline \multicolumn{2}{|l|}{ Educational level } \\
\hline Never been to school & $110(49.1)$ \\
\hline Primary & $62(27.7)$ \\
\hline Secondary & $22(9.8)$ \\
\hline Koranic & $27(12.1)$ \\
\hline Postsecondary & $3(1.3)$ \\
\hline \multicolumn{2}{|c|}{ Category of participant } \\
\hline $\begin{array}{l}\text { Malian gold-diggers, tombolomas and other } \\
\text { Malian workers }\end{array}$ & $130(58)$ \\
\hline Female sex workers & $27(12,1)$ \\
\hline Female non-sex workers & $54(24,1)$ \\
\hline Non-Malian gold-diggers & $13(5,8)$ \\
\hline \multicolumn{2}{|l|}{ Self-perceived health status } \\
\hline Good health status & $133(59,4)$ \\
\hline Ref: Poor health status & $91(40,6)$ \\
\hline \multicolumn{2}{|l|}{ Weekly earningsł } \\
\hline Earnings $\leq$ median & $112(50)$ \\
\hline Ref: Earnings > median & $112(50)$ \\
\hline \multicolumn{2}{|l|}{ Have worked in other IASGM before Kokoyo } \\
\hline Yes & $26(11.6)$ \\
\hline No & $198(88.4)$ \\
\hline
\end{tabular}

IASGM, informal artisanal small-scale gold mining.

†Age categories' cut-offs correspond to quartiles.

$\ddagger$ The median weekly earning is 14500 Francs de la Communauté Financière en Afrique (FCFA) (US\$25). This variable was used to account for the socioeconomic status of participants.

\section{HIV prevalence and new diagnoses}

Seventeen new HIV-positive cases were found with the ARCAD-SIDA testing, among those tested at the time of the survey, and $1 \mathrm{HIV}$-positive case was self-reported. Overall, HIV prevalence was $8 \%$ (95\% CI $4.5 \%$ to $11.6 \%)$. HIV prevalence was higher in women than in men, respectively, 10.4 (95\% CI $4.5 \%$ to $16.2 \%)$ and $5.9 \%$ (95\% CI $1.7 \%$ to $6.5 \%)$. In terms of the five different categories studied, the highest HIV prevalence was in women who were not sex workers (13\%; $95 \%$ CI $5.4 \%$ to $20.3 \%$ ). Although lower than in the latter group, the prevalence in female sex workers was still higher $(3.7 \%$; $95 \% \mathrm{CI}$ $-3.5 \%$ to $10.9 \%$ ) at the Kokoyo site than the national prevalence for sex workers (irrespective of gender). Prevalence in both non-Malian and Malian male gold-diggers was high, respectively, $7.7 \%$ (95\% CI $-7.4 \%$ to $22.8 \%$ ) $(90 \% \mathrm{CI}-4.9 \%$ to $20.4 \%)$ and $6.5 \%(95 \% \mathrm{CI}-0.7 \%$ to $13.7 \%$ ) (90\% CI $0.5 \%$ to $12.6 \%$ ), whereas prevalence in men other than gold-diggers was $6.4 \%$ (95\% CI $-0.7 \%$ to $13.5 \%)(90 \%$ CI $0.5 \%$ to $12.3 \%)$. No HIV-positive case was observed in traditional guards (tombolomas).

The quantitative survey showed that $63.4 \%$ participants (142 out of 224) had never had an HIV test. Of these, 7 (4.9\%)-five women and two men-tested positive for HIV using ARCAD-SIDA's test. This corresponded to $38.9 \%$ of the total 18 ( 11 women and 7 men) HIV-seropositive participants observed (or $45.5 \%(5 / 11)$ of total HIV women and $28.6 \%(2 / 7)$ of total HIV men). Among the five HIV-positive cases for women, one was a sand washer, one was a female sex worker and three were street vendors. Among the two HIV-positive cases for men, one was a non-Malian gold-digger and one a male street vendor.

\section{Factors associated with HIV seropositivity}

A multivariate probit regression was implemented to estimate the factors associated with HIV seropositivity among the 224 participants in the quantitative survey (table 2). Estimates show that the probability of HIV seropositivity was $7.8 \%(p=0.037)$ higher for female non-sex workers than for any other category, and this probability increased significantly with age. Indeed, the probability of HIV seropositivity - with respect to the youngest participants (aged between 18 and 21 years - was $14.1 \%(\mathrm{p}=0.034), 14.2 \%$ $(\mathrm{p}=0.036)$ and $16.1 \%(\mathrm{p}=0.021)$ higher for participants aged 22-26 years, 27-29 years and 30+ years, respectively. Finally, a $10.9 \%$ lower probability of HIV seropositivity was observed in participants who perceived their health status as good (vs poor).

\section{Main findings of the qualitative survey}

Five focus groups were carried out over 28 participants according to gender and professional status: six tombolomas, six Malian male gold-diggers, five non-Malian male gold-diggers, five female sex workers and six female non-sex workers. Among the discourses identified, one referred to sexual practices, especially non-systematic condom use, female sex workers charging extra for condomless sexual intercourse and the undisclosed use of condoms by women. Participants attributed these practices to the following factors: (1) the place where sexual intercourse took place: bars versus the street; (2) the nationality/ethnicity of female sex workers: Malians and Guineans were seen as more 'flexible' than Nigerians (considered as 'strict') with regard to condom use; 
Table 2 Factors associated with HIV seropositivity among participants living in the informal artisanal small-scale gold mining site of Kokoyo in Mali $(n=224)$

\begin{tabular}{|c|c|c|c|c|c|}
\hline \multirow[b]{2}{*}{ Covariates } & \multirow{2}{*}{$\begin{array}{l}\text { Marginal } \\
\text { Effects* }^{*}(\mathrm{dF} / \mathrm{dX})\end{array}$} & \multirow[b]{2}{*}{ Coefficient } & \multicolumn{2}{|l|}{$95 \% \mathrm{Cl}$} & \multirow[b]{2}{*}{ p Value } \\
\hline & & & Lower & Upper & \\
\hline Intercept & & -2.413 & -3.716 & -1.431 & $<0.001$ \\
\hline \multicolumn{6}{|l|}{ Category of participant } \\
\hline $\begin{array}{l}\text { Ref: Malian gold-diggers } \\
\text { and tombolomas }\end{array}$ & Ref. & Ref. & & & \\
\hline Female sex workers & 0.019 & 0.151 & -1.048 & 1.134 & 0.780 \\
\hline Female non-sex workers & 0.078 & 0.624 & 0.046 & 1.231 & 0.036 \\
\hline Non-Malian gold-diggers & -0.010 & -0.057 & -1.423 & 1.015 & 0.924 \\
\hline \multicolumn{6}{|l|}{ Age (years) $\dagger$} \\
\hline Ref: 18-21 & Ref. & Ref. & & & \\
\hline $22-26$ & 0.141 & 1.105 & 0.175 & 2.332 & 0.036 \\
\hline $27-30$ & 0.142 & 1.115 & 0.162 & 2.358 & 0.039 \\
\hline $30+$ & 0.161 & 1.268 & 0.271 & 2.548 & 0.022 \\
\hline \multicolumn{6}{|l|}{ Self-perceived health status } \\
\hline Good health status & -0.109 & -0.862 & -1.459 & -0.307 & 0.003 \\
\hline Ref: Poor health status & Ref. & Ref. & & & \\
\hline \multicolumn{6}{|l|}{ Weekly earnings $\ddagger$} \\
\hline Earnings $\leq$ median & 0.036 & 0.282 & -0.261 & 0.840 & 0.310 \\
\hline Ref: Earnings > median & Ref. & Ref. & & & \\
\hline
\end{tabular}

*Is the change in the probability given the discrete change for dichotomous variables.

†Age categories' cut-offs correspond to quartiles.

¥The median weekly earning is 14500 Francs de la Communauté Financière en Afrique (FCFA) (US\$25). This variable was used to account for the socioeconomic status of participants.

and (3) the nature of the relationship between men and women: trustful relationships (considered 'safer') than strictly commercial sex relationships (considered 'risky'). Another discourse identified referred to health services access, with the main barrier being the long distances involved. Other barriers mentioned were the high price of medicines, the lack of specialists and other healthcare providers, as well as the low number and poor quality of HIV/STI information/prevention programmes described. These barriers were also the main reasons why participants resorted to traditional medicine.

\section{DISCUSSION}

This is the first study conducted in an informal and artisanal small-scale gold mining site in Mali which investigates HIV in those directly involved in informal mining (ie, gold-diggers) and in other populations with a related activity. The aims of this article were drawn up specifically to respond to the need for the authorities of the IASGM site at Kokoyo to characterise the population living there, and to provide community-based prevention and HIV testing as part of the healthcare services offered.

The low educational level observed and the high proportion of participants living with revenues below the US $\$ 1.9$ poverty line threshold reflects the high level of poverty reported in the literature concerning
IASGM sites in other countries with large gold-bearing zones. ${ }^{22} 32$ The fluctuation of the population at Kokoyo suggests large-scale cyclical migration of workers (ie, they stay for a period, go back home and the next season they return either to the same mine or to another). Rees et al suggested such workers are often separated from their family (ie, geographically single), ${ }^{12}$ something confirmed by our results where $71.5 \%$ of Malian participants came from other regions of Mali (non-autochthonous), and $40.6 \%$ of the total sample was not Malian. Moreover, geographically single individuals accounted for $49.4 \%$ of the 158 participants who reported being married or living in a couple. This 'bridge population' cohabits with other high-risk groups in the IASGM site at Kokoyo, representing a potential source for the continued spread of infectious diseases-including HIV—at the site, and at their home. ${ }^{45}$ Indeed, being single (geographically or not) is associated with risky behaviours, given the freedom from social norms and the economic difficulties that prevail in IASGM sites. ${ }^{2}$ Furthermore, working conditions and the inherent related dangers which male gold-diggers are confronted with have also been identified as factors related to an increase in risky behaviours. ${ }^{33}$

This is the first time that HIV prevalence has been estimated in an IASGM site in Mali. We found a prevalence of $8 \%$ in the 224 participants in our study, which is much 
higher than the Malian national prevalence of $1.3 \%$ estimated in $2015,{ }^{34}$ but is in line with the $7 \%$ estimated for the IASGM site of Tenkoto in the Kédougou region of Senegal. ${ }^{35}$ In addition, HIV prevalence varied for the different categories studied, ranging from $3.6 \%$ for female sex workers to $13 \%$ for both female gold-diggers and female street vendors. The latter value is in line with the $13 \%$ estimated for street vendors in Burkina Faso, although that value was not specific to IASGM sites. ${ }^{36}$ Our estimates reflect the results from the few qualitative studies performed to date which suggest high prevalence of HIV in IASGM sites, and highlight that 'less classic' groups (ie, those not directly involved in mining) are at higher risk. ${ }^{2}$ The different HIV prevalence rates found across groups may reflect the lack of prevention programmes adapted to key populations other than sex workers in Mali. Most of the efforts in the fight against HIV/AIDS in Mali are concentrated on female sex workers and men having sex with other men, who are identified as the most vulnerable groups. This could explain-at least in part-the low prevalence rate among female sex workers in Kokoyo IASGM and the higher prevalence among other groups, including female non-sex workers and gold-diggers. Indeed, participants from these two categories expressed during the focus groups that prevention campaigns are mostly directed at female sex workers, who seem to be more informed about the risk of HIV contamination and about prevention tools.

The acceptability of HIV testing by participants observed in this study demonstrated that the community-based dimension is crucial to conduct this kind of research, ${ }^{27}$ and that it is also useful for the provision of prevention and HIV testing to this population. Of the 236 persons invited to test for HIV, only $5 \%$ refused. This is one of the main contributions of our analysis, and highlights the large demand-supply gap for healthcare services in Kokoyo. Indeed, the nearest Rural Health Community Centre (Centre de Santé Communautaire) does not provide either prevention or testing for HIV, and the only two centres of voluntary testing in the Koulikoro region are far from gold-bearing zones, especially the IASGM site of Kokoyo. This community-based research identified a large number of new HIV-positive cases, and this is another important contribution of the study. More specifically, $38 \%$ of the 18 HIV-positive participants in the quantitative survey were newly diagnosed using ARCAD-SIDA's rapid tests. Five out of 11 positive cases in women were new diagnoses, especially female street vendors. Although ARCAD-SIDA referred all 18 HIV-positive participants to the nearest regional hospitals (CSREF) in order to link them to care, the emerging question is whether or not these participants subsequently initiated and adhered to antiretroviral treatment given the distance of more than $100 \mathrm{~km}$ between Kokoyo and Kangaba city where the CSREF is located. Unfortunately, we have no information about lost to follow-up rates in people living with HIV in the context of IASGM sites, but presumably these rates are high given that HIV is not of primary concern to people in IASGM sites, as suggested by Campbell. ${ }^{3}$ This certainly seems to be the situation in Kokoyo, where the large majority of study participants aware of HIV (over $90 \%)$ had never previously gone for a test $(63.4 \%)$. Multivariate analyses indicated that female non-sex workers, the eldest participants and those with poor self-perceived health status were the three subpopulations most associated with HIV seropositivity.

Some limitations should be acknowledged. First, the study sample is not representative of the whole population in IASGM sites in Mali. However, our results reflect those in the literature. Second, the cross-sectional design of the Sanu Gundo survey did not enable us to analyse changes over time concerning different aspects, such as living and working conditions, seasonal mobility and sexual behaviour. Furthermore, although the participants who tested positive for HIV during the study were referred to the regional hospital, the design of the survey did not allow us to collect subsequent information, either concerning linkage to care or antiretroviral treatment initiation. Finally, there is a possibility of selection bias, as the sample was drawn from the healthcare conversation audience organised by ARCAD-SIDA. Nevertheless, any selection bias would reflect an audience mainly comprising individuals interested in prevention and to some extent, worried about health issues, especially HIV. One would expect that any future study whose design was to attract participants other than those already interested in healthcare, would result in higher HIV prevalence being measured and would accentuate the precarious characteristics already described by our survey at Kokoyo. Despite these limitations, our study contributes to the existing literature by creating a knowledge base which could be a useful first step for the development of suitable surveys and interventions.

\section{CONCLUSION}

The results of this study demonstrate the importance of focusing on different categories of workers and the necessity to conduct further similar research on other Malian IASGM sites, in order to account for structural and geographical heterogeneity. The present article contributes to the literature by reopening the debate about the impact of health issues on IASGM activities, especially HIV issues, in a context where the sustained spread of this disease could harm efforts in the fight against AIDS and have important negative consequences on one of the main cornerstones of the Malian economy. Integrated policymaking should pay special attention to infectious diseases among populations in IASGM zones. Bringing information/prevention activities closer to people working in gold-bearing zones is an urgent public health action.

\section{Author affiliations}

${ }^{1}$ Aix Marseille Univ, INSERM, IRD, SESSTIM, Sciences Economiques \& Sociales de la Santé \& Traitement de l'Information Médicale, Marseille, France 
${ }^{2}$ ORS PACA, Observatoire Régional de la Santé Provence-Alpes-Côte d'Azur, Marseille, France

${ }^{3}$ ARCAD SIDA, Bamako, France

${ }^{4}$ University Lyon 2, Institute of Psychology, Social Psychology Research Group (EA 4163), Mendès-France, Bron, France

Contributors LST designed and led the study and wrote the first draft of the report. LST, MSM, BS and BDK designed the analysis. LST, HB, NK and FD analysed the data. MM and MB oversaw data management. All authors critically reviewed and approved the manuscript.

Funding The Sanu Gundo survey was sponsored and funded by the French National Agency for Research on AIDS and Viral Hepatitis (ANRS) grant ANRS12339 Sanu Gundo.

Competing interests None declared.

Patient consent Obtained.

Ethics approval French (CCTIRS No. 15.917) and Malian (No. 2015/65/CE/FMPOS) ethics committees.

Provenance and peer review Not commissioned; externally peer reviewed.

Data sharing statement Full data set and statistical code available from the corresponding author luis.sagaon-teyssier@inserm.fr The presented data are anonymised and risk of identification is null.

Open Access This is an Open Access article distributed in accordance with the Creative Commons Attribution Non Commercial (CC BY-NC 4.0) license, which permits others to distribute, remix, adapt, build upon this work non-commercially, and license their derivative works on different terms, provided the original work is properly cited and the use is non-commercial. See: http://creativecommons.org/ licenses/by-nc/4.0/

( ) Article author(s) (or their employer(s) unless otherwise stated in the text of the article) 2017. All rights reserved. No commercial use is permitted unless otherwise expressly granted.

\section{REFERENCES}

1. A Simple Public Health Strategy for ASGM - Artisanal Gold Council. 2014. http://www.artisanalgold.org/publications/articles/a-simplepublic-health-strategy-for-asgm (accessed 28 Aug 2016)

2. Desmond N, Allen CF, Clift S, et al. A typology of groups at risk of HIV/STI in a gold mining town in north-western Tanzania. Soc Sci Med 2005;60:1739-49.

3. Campbell C. Migrancy, masculine identities and AIDS: the psychosocial context of HIV transmission on the South African gold mines. Soc Sci Med 1997;45:273-81.

4. Cates W, Dallabetta G. The staying power of sexually transmitted diseases. Lancet 1999;354(Suppl 4):SIV62.

5. Jokonya O. Towards a Big Data Framework for the Prevention and Control of HIV/AIDS, TB and silicosis in the mining industry. Procedia Technology 2014;16:1533-41.

6. Kis $A D$. $A B C$ for AIDS prevention in Guinea: migrant gold mining communities address their risks. AIDS Care 2010;22:520-5.

7. Day JH, Miyamura K, Grant AD, et al. Attitudes to HIV voluntary counselling and testing among mineworkers in South Africa: will availability of antiretroviral therapy encourage testing? AIDS Care 2003;15:665-72.

8. Sikasote J, Grant L, Chinn DJ, et al. Voluntary counselling and testing for HIV in a Zambian mining community: serial interviews with people testing negative. Sex Transm Infect 2011;87:433-8.

9. Lightfoot E, Maree M, Ananias J. Exploring the relationship between HIV and alcohol use in a remote Namibian mining community. Afr $J$ AIDS Res 2009;8:321-7.
10. Siu GE, Seeley J, Wight D. Dividuality, masculine respectability and reputation: How masculinity affects men's uptake of HIV treatment in rural eastern Uganda. Soc Sci Med 2013;89:45-52.

11. Siu GE, Wight D, Seeley J. How a masculine work ethic and economic circumstances affect uptake of HIV treatment: experiences of men from an artisanal gold mining community in rural eastern Uganda. J Int AIDS Soc 2012;15 Suppl 1:1-9.

12. Rees D, Murray J, Nelson G, et al. Oscillating migration and the epidemics of silicosis, tuberculosis, and HIV infection in South African gold miners. Am J Ind Med 2010;53:398-404.

13. Stevens W, Apostolellis A, Napier G, et al. HIV/AIDS prevalence testing-merits, methodology and outcomes of a survey conducted at a large mining organisation in South Africa. S Afr Med J 2008;96:134.

14. Diallo B-L, Alary M, Rashed S, et al. ?pid?mie du VIH chez les hommes travaillant dans les mines industrielles de Guin?e? s? ropr?valence, facteurs de risque associ?s et tendance 2001?2007. Revue d'?pid?miologie et de Sant? Publique 2011;59:251-7.

15. Palmer $\mathrm{CJ}$, et al. HIV prevalence in a gold mining camp in the Amazon region. Guyana, 2002.

16. Clift S, Anemona A, Watson-Jones D, et al. Variations of HIV and STI prevalences within communities neighbouring new goldmines in Tanzania: importance for intervention design. Sex Transm Infect 2003;79:307-12.

17. Traore M. Some critical reflections on the future of gold mining in Mali. : The Extractive Industries and Society, 2016:3: 367-9.

18. Bastagli F, Toulmin C. European Parliament \& Directorate-General for External policies of the Union. Mali, the economic factors behind the crisis: Publications Office, 2014

19. Initiative pour la transparence dans les industries extractives ITIEMali: rapport ITIE pour l'année 2013, 2013.

20. Keita S. Study on artisanal and small-scale mining in Mali. MMSD Work. Pap 2001;80.

21. Hilson G, McQuilken J. Four decades of support for artisanal and small-scale mining in sub-Saharan Africa: a critical review. : The Extractive Industries and Society, 2014:1: 104-18.

22. Buxton A. Responding to the challenge of artisanal and small-scale mining: Can Knowl Netw Help, 2013.

23. Teschner BA. ?Orpaillage pays for everything?: How artisanal mining supported rural institutions following Mali's coup d??tat. Futures 2014;62:140-50.

24. Verbrugge B. Voices from below: artisanal- and small-scale mining as a product and catalyst of rural transformation. J Rural Stud 2016;47:108-16.

25. Onukwugha E, Bergtold J, Jain R. A primer on marginal effects--Part I: theory and formulae. Pharmacoeconomics 2015;33:25-30.

26. Onukwugha E, Bergtold J, Jain R. A primer on marginal effectspart II: health services research applications. Pharmacoeconomics 2015;33:97-103.

27. Greene WH. Econometric analysis: Pearson Prentice Hall, 1997.

28. R Core Team. R: a language and environment for statistical computing: R Foundation for Statistical Computing, 2016.

29. Flick U. Managing quality in qualitative research. Sage 2008.

30. Caillaud S, Kalampalikis N. Focus groups and Ecological Practices: a psychosocial approach. Qual Res Psychol 2013;10:382-401.

31. Ratio de la population pauvre en fonction Du Seuil de pauvreté national (\% de la population rurale) | data. http://donnees. banquemondiale.org/indicateur/SI.POV.RUHC?locations=ML (accessed 22 Aug 2016).

32. Yakovleva N. Perspectives on female participation in artisanal and small-scale mining: a case study of Birim North District of Ghana. Resources Policy 2007;32:29-41.

33. Bellaby P. To risk or not to risk? uses and Limitations of Mary Douglas on Risk-Acceptability for understanding Health and Safety at Work and Road Accidents. Sociol Rev 1990;38:465-83.

34 . Mali | UNAIDS. http://www.unaids.org/en/regionscountries/ countries/mali (accessed 22 Aug 2016)

35. Focus sur Bantako, zone d'orpaillage traditionnelle: La vulnérabilité au VIH dans les zones d'orpaillages traditionnelles, 2009.

36. Programme d'appui au monde associatif et communautaire (PAMAC): pour la période 2011-2015, 2011. 